\title{
The Promoting Effect of Traumatic Brain Injury on the Incidence and Progression of Glioma: A Review of Clinical and Experimental Research
}

\author{
Yu-Long Lan $\mathbb{D}^{1-3}$ \\ Yongjian Zhu (1D) \\ Gao Chen' \\ Jianmin Zhang'
}

'Department of Neurosurgery, Second Affiliated Hospital, School of Medicine, Zhejiang University, Hangzhou, People's Republic of China; ${ }^{2}$ Department of Neurosurgery, The Second Affiliated Hospital of Dalian Medical University, Dalian, People's Republic of China; ${ }^{3}$ Department of Neurosurgery, Shenzhen People's Hospital, Shenzhen, People's Republic of China
Correspondence: Yu-Long Lan

Department of Neurosurgery, Second Affiliated Hospital, School of medicine,

Zhejiang University, Hangzhou, 310000,

People's Republic of China

Tel +86 I8858I95203

Email lanyulong@zju.edu.cn

Jianmin Zhang

Department of Neurosurgery, Second

Affiliated Hospital, School of medicine,

Zhejiang University, Hangzhou, 310000 ,

People's Republic of China

Tel +86 I3805722695

Email zjmI35@zju.edu.cn

\begin{abstract}
The role of traumatic brain injury in the development of glioma is highly controversial since first presented. This is not unexpected because traumatic brain injuries are overwhelmingly more common than glioma. However, the causes of post-traumatic glioma have been long discussed and still warrant further research. In this review, we have presented an overview of previous cohort studies and case-control studies. We have summarized the roles of microglial cells, macrophages, astrocytes, and stem cells in posttraumatic glioma formation and development, and reviewed various carcinogenic factors involved during traumatic brain injury, especially those reported in experimental studies indicating a relationship with glioma progression. Besides, traumatic brain injury and glioma share several common pathways, including inflammation and oxidative stress; however, the exact mechanism underlying this co-occurrence is yet to be discovered. In this review, we have summarized current epidemiological studies, clinical reports, pathophysiological research, as well as investigations evaluating the probable causes of co-occurrence and treatment possibilities. More efforts should be directed toward elucidating the relationship between traumatic brain injury and glioma, which could likely lead to promising pharmacological interventions towards designing therapeutic strategies.
\end{abstract}

Keywords: traumatic brain injury, glioma, promotion, mechanism

\section{Introduction}

Traumatic brain injury is a leading global cause of mortality and morbidity and the main cause of death in young people living in industrialized countries. ${ }^{1,2}$ Traumatic brain injury is mainly caused by an external mechanical force causing brain trauma. Traumatic brain injury and the ensuing neuroinflammation, in addition to causing motor and cognitive deficits, may persist long after the initial injury. ${ }^{3}$ Furthermore, long-term neuroinflammation has been related to increased risk of neurodegenerative disorders and various other deficits. ${ }^{4}$ Traumatic brain injury as a risk factor for brain tumors has been a controversial topic in medicine for over a century. ${ }^{5-8}$ However, as statistical reports on brain tumors often exclude post-traumatic glioma, relevant information on the incidence of gliomas caused by traumatic brain injuries is rare. Although previous clinical studies and case reports are often vague and difficult to evaluate since most of them were published so many years ago, ${ }^{5-12}$ some are quite striking, such as the cohort study by Munch et $\mathrm{al}^{5}$ in which the reduced long-term risk of malignant astrocytic tumors after structural brain injury was evaluated. However, this study was conducted using a small population. Furthermore, it is to be noted that traumatic brain 
Graphical Abstract

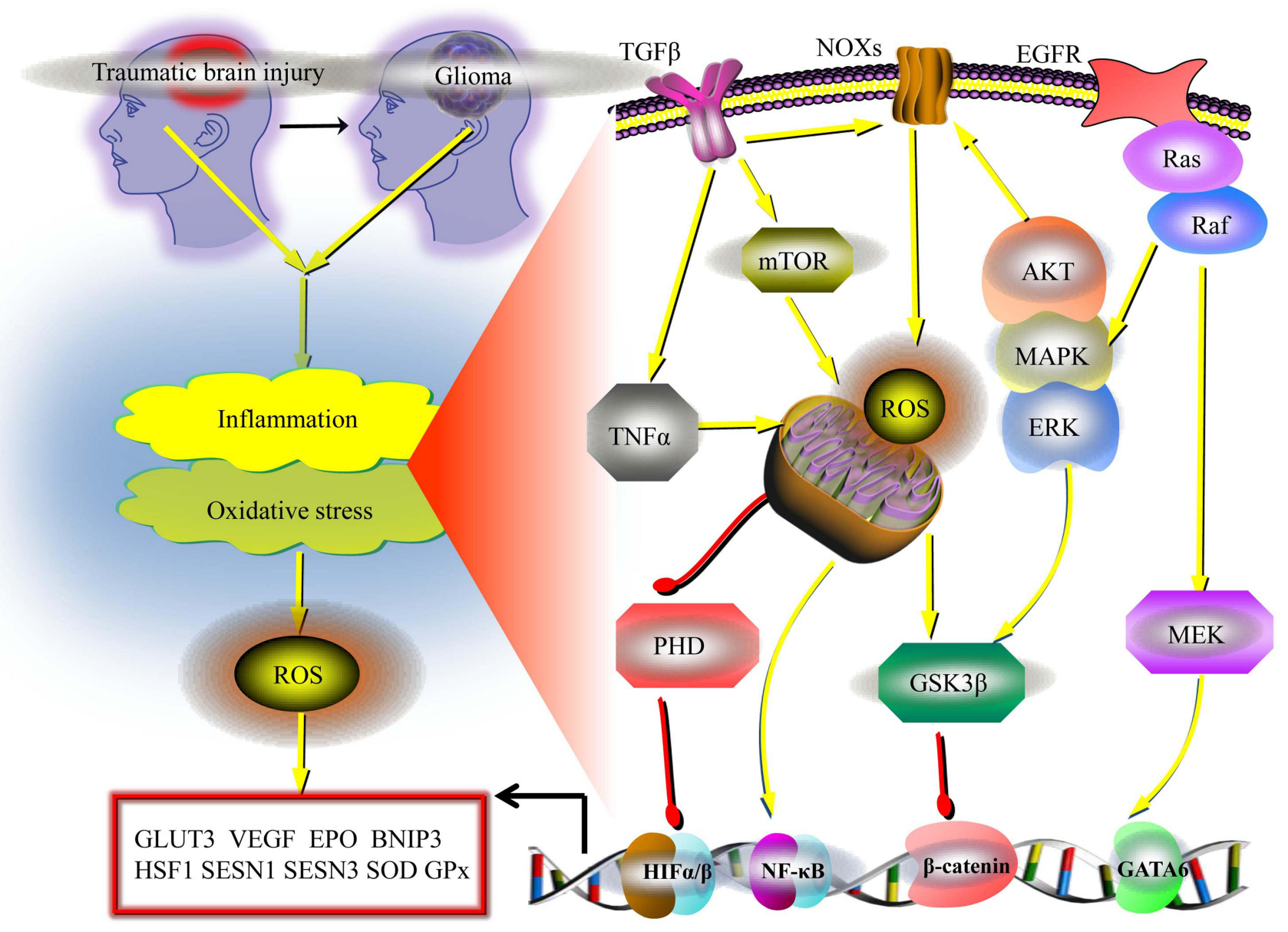

injury is only one type of structural brain injury in this study. Additionally, it is challenging to confirm the incidence of post-traumatic glioma owing to the frequently considerable time gap between traumatic brain injury and glioma. Thus, there is an urgent need to systematically evaluate the role and outcome of head trauma in the incidence and progression of glioma. In this review, our primary focus is to document the interrelationship between traumatic brain injury and glioma based on a comprehensive review of the existing literature, which is discussed in detail. First, we present an overview of previous cohort studies and various case reports regarding the relationship between traumatic brain injury and glioma. Next, we discuss the roles of microglial cells, macrophages, astrocytes, and stem cells in post-traumatic glioma formation and development. Moreover, we also briefly discuss the various carcinogenic factors during traumatic brain injury that could explain the interplay between these two parameters. We have also summarized the common inflammatory and oxidative stress-related signaling pathways related to traumatic brain injury and glioma. Lastly, we have elaborated on the strategy that could be considered in a clinical setting, and have concluded this review with directions for future research.

\section{An Overview of Previous Epidemiological Studies}

All previously published cohort studies and case-control studies are not directly comparable owing to differences in exposures and outcomes (Table 1). A population-based study by Inskip et $\mathrm{al}^{8}$ reveals an increased overall incidence of intracranial tumors of head trauma patients, whereas no significant association was found in the case of malignant astrocytic tumors. In a cohort study by Nygren et $\mathrm{al}^{7}$ no significant association between traumatic brain injuries and brain tumors was identified; moreover, 
Table I Overview of Published Epidemiological Studies Exploring the Causal Relationship Between Traumatic Brain Injury and Glioma

\begin{tabular}{|c|c|c|c|c|c|c|}
\hline Series & $\begin{array}{l}\text { Study } \\
\text { Design }\end{array}$ & Region & Age & $\begin{array}{l}\text { Cohort Study: } \\
\text { Participants; Glioma } \\
\text { Cases; Mean Follow- } \\
\text { Up } \\
\text { Case-Control Study: } \\
\text { Cases/Controls }\end{array}$ & $\begin{array}{l}\text { Data } \\
\text { Collection }\end{array}$ & Risk Estimates \\
\hline Inskip $1998^{8}$ & Cohort & Denmark & $\begin{array}{l}22.5 \\
\text { (Mean) }\end{array}$ & $\begin{array}{l}\text { 224,42I patients; } 79 \\
\text { glioma cases; Mean } \\
\text { follow-up } 8 \text { years }\end{array}$ & Follow up & SIR, I.0 (0.80-1.20) \\
\hline Nygren $2001^{7}$ & Cohort & Sweeden & $\begin{array}{l}32.2 \\
\text { (Mean) }\end{array}$ & $\begin{array}{l}311,006 \text { patients; } 161 \\
\text { glioma cases; Mean } \\
\text { follow-up } 10.4 \text { years }\end{array}$ & Follow up & SIR, I.0 (0.90-I.20) \\
\hline Chen $2012^{6}$ & Cohort & Taiwan & $\begin{array}{l}43.5 \\
\text { (Mean) }\end{array}$ & $\begin{array}{l}5007 \text { patients; } 9 \text { glioma } \\
\text { cases; Mean follow-up } 3 \\
\text { years }\end{array}$ & Follow up & SIR, $2.08(1.27-3.22)$ \\
\hline Munch $2015^{5}$ & Cohort & Denmark & $\begin{array}{l}51 \\
\text { (Mean) }\end{array}$ & $\begin{array}{l}48,194 \text { patients; } 14 \\
\text { glioma cases; Median } \\
\text { follow-up } 28 \text { years }\end{array}$ & Follow up & RR, I.99 (I.00-3.50) \\
\hline $\begin{array}{l}\text { Hochberg } \\
1984^{12}\end{array}$ & $\begin{array}{l}\text { Case- } \\
\text { control }\end{array}$ & USA & $|5-8|$ & $125 / 113$ & Questionnaire & $\begin{array}{l}<15 y r s: \text { RR, I.I }(0.40-3.20) \text { for mild trauma; RR, } \\
\text { I.2 (0.30-5.60) for severe trauma } \\
\geq 15 y r s: \text { RR, I.4 }(0.40-4.70) \text { for mild trauma; RR, } \\
\text { I0.6 (2.10-53.30) for severe trauma }\end{array}$ \\
\hline $\begin{array}{l}\text { Zampieri } \\
1994^{9}\end{array}$ & $\begin{array}{l}\text { Case- } \\
\text { control }\end{array}$ & Italy & $18-70$ & $195 / 195$ & Questionnaire & $\begin{array}{l}\text { OR, } 0.7(0.30-1.40) \text { for all glioma types; OR, I.2 } \\
(0.30-5.00) \text { for low-grade glioma; OR, o.5 }(0.20- \\
\text { I.30) for high-grade glioma }\end{array}$ \\
\hline $\mathrm{Hu} 1998^{\prime \prime}$ & $\begin{array}{l}\text { Case- } \\
\text { control }\end{array}$ & $\begin{array}{l}\text { Northest } \\
\text { China }\end{array}$ & $\begin{array}{l}\text { Not } \\
\text { found }\end{array}$ & $218 / 436$ & $\begin{array}{l}\text { In-person } \\
\text { interview or } \\
\text { questionnaire }\end{array}$ & OR, $4.09(2.5 \mathrm{I}-10.3 \mathrm{I})$ \\
\hline $\begin{array}{l}\text { Preston- } \\
\text { Martin } 1998^{10}\end{array}$ & $\begin{array}{l}\text { Case- } \\
\text { control }\end{array}$ & $\begin{array}{l}\text { Six } \\
\text { countries }\end{array}$ & $20-79$ & $1178 / 1987$ & Questionnaire & $\begin{array}{l}\text { Male: I.I8 }(0.94-I .48) \text { for any trauma; } 1.13 \\
(0.87-I .48) \text { for serious trauma } \\
\text { Female: } 1.03(0.42-2.55) \text { for any trauma; } 1.07 \\
(0.74-1.56) \text { for serious trauma }\end{array}$ \\
\hline
\end{tabular}

Abbreviations: SIR, standardized incidence ratio; RR, relative risk; OR, odds ratio.

specific risks for malignant astrocytic tumors were not reported. However more recently, a cohort study by Chen et $\mathrm{al}^{6}$ indicated an increased risk for not otherwise specified malignant brain tumors within 3 years after a traumatic brain injury. Besides, interestingly, a research group demonstrated a decreased risk 5 or more years after structural brain injury; however, they did not find convincing evidence for an association between structural brain injury and malignant astrocytic tumors within the first 5 years of follow-up. ${ }^{5}$ The authors speculated that the inflammatory response after traumatic injury could cause elevated immunological alertness for astrocytes undergoing neoplastic transformation, as well as a clearance of premalignant astrocytes or neural stem cells, which may otherwise have developed into glioma. Although their study demonstrated that structural brain injury may generally reduce the long-term risk of malignant astrocytic tumors, their data also supported that structural brain injury specifically caused by trauma (different from other types of exposures such as cerebral ischemic infarction and intracerebral hemorrhage) could increase the long-term risk of malignant astrocytic tumors. Thus, the relationship between traumatic brain injury and glioma is still not conclusive and warrants further studies. 
It is often a challenge to compare the results of pre-

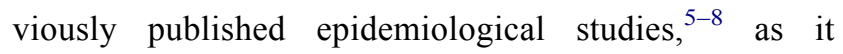
involves individuals of different ages who live in different environments. Importantly, most studies have also not been standardized regarding the type or the severity of brain damage. The low incidence of brain tumors also hinders the design of relevant research. There is currently an urgent need for more comprehensive and larger-scale epidemiological investigations, including cohort studies and case-control studies, to evaluate post-traumatic glioma. To date, very few case-control studies have specifically reported the risk for malignant astrocytoma/ glioma after traumatic brain injury, and conclusively, the currently available findings are equivocal with null ${ }^{9,10}$ or positive associations. ${ }^{11,12}$ For the first time, Hochberg et $\mathrm{al}^{12}$ have done a case-control study of 160 persons with glioblastoma, and the results suggested that severe head trauma in adults is a significant risk factor for glioblastoma. After that, Zampieri et $\mathrm{al}^{12}$ did another case-control study to find potential risk factors for cerebral glioma in adults, however, their study yielded no meaningful association between head trauma and glioma. Besides, the case-control study done by Preston-Martin et $\mathrm{al}^{10}$ investigated the role of head trauma from injury in adult brain tumor risk. Although not significant association between head trauma and glioma has been found, their findings suggest that an association between head trauma and brain tumor risk cannot be ruled out and should therefore be further studied, and future studies of head trauma and brain tumor risk should consider potential initiators of carcinogenesis, such as nitrite from cured meats, as modifiers of the trauma effect on risk of brain tumor. Furthermore, $\mathrm{Hu}$ et $\mathrm{al}^{11}$ also exerted case-control study of risk factors for glioma in adults, interestingly positive associations between brain trauma and glioma has been found. Unfortunately, all case-control studies were conducted before the year 1998, and no newly published research worthy of reference could be found suitable for discussion in this review. The advantages of cohort studies have been highlighted in various studies; therefore, most researchers give more weightage to cohort studies than case-control studies when systematically evaluating evidence. $^{13,14}$ Thus, additional more cohort investigations with correct and standardized study designs are much needed to gain a better understanding of posttraumatic glioma.

\section{An Overview of Previous Case Reports}

The results of the published epidemiological studies could not be compared uncritically, as the types of brain injuries differed, and patients belonged to different ethnic groups and different ages. Difficulties in conducting epidemiological studies can be attributed to the low incidence of brain tumors. More efforts should be directed toward investigating the causal relationship between traumatic brain injury and glioma, which is supported by several published case reports. ${ }^{15-27}$ Although these reports from epidemiological observations have not conclusively confirmed the relationship between traumatic brain injury and glioma, ${ }^{5-8}$ some reports discuss the follow-up details of patients in great detail and are indicative of the possibility of such a relationship. ${ }^{15-27}$ Anselmi et $\mathrm{al}^{15}$ reported two cases of brain glioma that developed in the scar of an old brain trauma, these two cases fulfill the established criteria for a traumatic origin of brain tumors and add further support to the relationship between cranial trauma and the onset of glioma. Di Trapani et $\mathrm{al}^{16}$ reported that several years after sustaining a commotive left parietal trauma, one patient developed a mixed glioma in the left temporo-parietaloccipital region in continuity with the scar resulting from the trauma. Magnavita et $\mathrm{al}^{17}$ reported the case of a patient who suffered a severe head injury to the right temporoparietal lobe, and the patient developed a glioblastoma multiforme at the precise site of the meningocerebral scar 4 years later. Moorthy et $\mathrm{al}^{18}$ reported a case of a 56 -yearold man who had history of head injury 5 years prior with $\mathrm{CT}$ evidence of bilateral basifrontal contusions. Imaging showed a large left frontal intra-axial mass lesion and the histopathology was reported as glioblastoma multiforme. The authors formulated additional radiologic criteria for tumors that may present following trauma. Mrowka et al ${ }^{19}$ reported that a glioblastoma multiforme developed 30 years after a penetrating craniocerebral injury in the left parietal region caused by fragments of an artillery projectile. Sabel et $\mathrm{al}^{20}$ reported that a patient developed a leftsided frontal glioblastoma multiforme at the precise site of the meningocerebral scar and posttraumatic defect 37 years later. Witzmann et $\mathrm{al}^{21}$ reported a case of a 28 -yearold male who suffered a frontal penetrating gunshot injury with subsequent bifrontal brain abscess and subdural empyema, and five years later developed a large bifrontal glioblastoma multiforme at the precise site of the meningo-cerebral scar and posttraumatic defect. Zhou 
et $\mathrm{al}^{22}$ also reported one case of glioblastoma multiforme that developed in the scar of an old brain trauma 10 years ago. Han et $\mathrm{al}^{23}$ presented the first case of pregnancyrelated post-traumatic malignant glioma in a 29 -year-old female, and suggested that pregnancy may promote the manifestation of the clinical symptoms. Tyagi et $\mathrm{al}^{24}$ used radiographic evidence from two patients to assess the possibility of a link between TBI and glioblastoma multiforme. Salvati et $\mathrm{al}^{25}$ presented 4 cases of posttraumatic glioma with radiological evidence of absence of tumor at the time of the injury. Henry et $\mathrm{al}^{26}$ reported a case of post-traumatic malignant glioma with radiological evidence of only a contusion prior to the development of the glioma. Simińska et $\mathrm{al}^{27}$ reported one case of posttraumatic glioma 2 years after head injury. Overall, some data from these studies might support the conclusion that the association is almost weak, while others not; but a causal relationship between traumatic brain injury and glioma is highly possible. This is because traumatic brain injury initiates inflammation, oxidative stress, repair, oncogene activation, and other pathophysiological changes, which are bound to lead to malignancy in at least some patients. ${ }^{28,29}$

Besides, to better identify reported cases addressing the relationship between traumatic brain injury and the incidence and development of glioma, an important aspect is to be able to recognize and differentiate between a tumor, traumatic brain injury-induced glioma, and post-traumatic glioma. We believe that only specific cases that fulfill certain conditions or criteria, could add to revealing the etiological association between head trauma and glioma. Thus, more efforts should be directed in establishing if there is a relationship between traumatic brain injury and gliomas, as well as diagnosing post-traumatic glioma. Since traumatic incidents are much more frequent than a possibly related tumor, James Ewing ${ }^{30}$ defined five criteria that could aid in the identification of post-traumatic glioma that could contribute to establishing the relationship between brain injury and the subsequent glioma. Subsequently, Zulch and Manuelidis ${ }^{31}$ revised Ewing's criteria while adding their viewpoints. And Moorthy and Rajshekhar ${ }^{32}$ further added imaging-related screening criteria to this list. We believe that specific cases that fulfill these criteria, as well as possibly other cases with accurate retrospective data of traumatic brain injury and high risk of developing glioma, could add to the clarification of the etiological association between traumatic brain injury and glioma.

\section{Role of Microglial Cells}

Neuroinflammation accompanying the activation of microglial cells and other effector cells has been suggested as an important mechanism of TBI. ${ }^{33}$ Active microglial cells can transform to the M1 phenotype, to secrete proinflammatory or cytotoxic mediators that mediate post-TBI cell death and neuronal dysfunction, or to the M2 phenotype, to participate in phagocytosis and secrete antiinflammatory cytokines and neurotrophic factors that are important for neural protection and repair. ${ }^{34}$ Indeed, they can become polarized ranging from the classic M1 phenotype to an alternative M2 phenotype after TBI. ${ }^{35}$ The M1 response is presumed to be pro-inflammatory, ${ }^{36}$ whereas the M2 phenotype owns anti-inflammatory effects. ${ }^{37}$ Multiple molecular pathways, such as STAT, nuclear factor- $\mathrm{\kappa B}(\mathrm{NF}-\mathrm{\kappa B})$, and interferon regulatory factor (IRF), are involved in the regulation of M1/M2 phenotypic transitions. ${ }^{38-40}$ Preclinical evidence indicated that mixed phenotypes are present in the pathological processes of TBI, which offer opportunities for therapeutic interventions. $^{41}$

Several mechanisms have been shown to be associated with the formation of post-traumatic glioma, specifically, inflammatory processes and oxidative stress, both of which are mainly involved in the removal of damaged components from the brain and are known to play irreplaceable roles in this process. ${ }^{24}$ In the brain, these mechanisms are mainly mediated by the microglia or other cells of the immune system. ${ }^{24,42}$ Microglia in the brain play a role in phagocytosis and antigen presentation, leading to the release of chemokines or cytokines. ${ }^{43}$ Interestingly, recent in vivo studies have shown that microglia could have different effects on the development of brain glioma, and also result in immunosuppressive conditions that promote glioma development. ${ }^{44,45}$ Although the growth-promoting effect of glioma by microglia after traumatic brain injury is controversial, its significant role in promoting an environment that can facilitate glioma development has been identified. ${ }^{43}$ Microglia can produce metalloproteinases in the tissues adjacent to glioma, which can facilitate tumor invasion. ${ }^{44}$ Besides, PGE2 can also contribute to the creation of an environment that facilitates glioma development. ${ }^{46}$ PGE2 is released by the microglia accompanying the developing glioma and can suppress $\mathrm{T}$ lymphocytes. The net effect is a decreased expression of major histocompatibility complex (MHC) class II molecules on antigen-presenting cells. ${ }^{46}$ Brain-repair processes 
mainly involve the microglia in normal conditions; however, during traumatic brain injury, various other cells from the immune system can also enter the brain parenchyma along with blood. These effects cannot be ignored.

\section{Role of Macrophages}

Oxidative stress caused by ROS in the acute phase of TBI and cerebral infarction is thought to be detrimental, and macrophages have been recognized as the main cells that produce ROS. ${ }^{47}$ During traumatic brain injury, macrophages migrate to the site of the damaged blood-brain barrier and secrete interleukin 6 (IL-6). In normal conditions, the expression of IL-6 is very low, whereas, during traumatic brain injury, its production increases considerably. ${ }^{48}$ Brain injury elevates IL-6 production in both serum and CSF to high concentration. Notably, multiple TBI patients' samples have also showed that the combination of elevated IL-6 concentrations is correlated with better outcomes in patients with TBI, suggesting IL- 6 as a new therapeutic strategy as well as for prediction of disease outcome of patients with TBI. ${ }^{49}$ Importantly, high levels of IL-6 in the brain generally result in an adverse impact on microcirculation and lead to the destruction of the blood-brain barrier in an obviously wider area compared to the initial area of trauma. ${ }^{27}$ Thus, in traumatic brain injuries, it is crucial that the blood-brain barrier is not initially compromised, as IL-6 can subsequently promote the entry of macrophages to the site of injury and aggravate brain edema. ${ }^{24,42}$ Besides, $\mathrm{Xu}$ et al reported that IL-6 also impacts cell-cycle regulation ${ }^{42}$ and activates signal transducer and activator of transcription-3 (STAT3), which is important for cell proliferation, differentiation, and apoptosis. Previous studies show that STAT3 inhibition suppresses the growth of glioma cells and promotes apoptosis. ${ }^{43}$ These findings have also been confirmed in other in vivo studies. ${ }^{50,51}$ Besides, STAT3 activation can inhibit T lymphocytes and MHC II molecules on microglial and other antigen-presenting cells. ${ }^{43}$ Thus, STAT3 has an immunosuppressive effect and is likely a carcinogenic factor for glioma. Importantly, the increased concentrations of IL-6 and its receptors in the cerebrospinal fluid of patients who underwent traumatic brain injury are indicative of the involvement of IL-6 in glioma progression. ${ }^{42,43}$

\section{Role of Neuronal Stem Cells}

The neuronal stem cells in the brain are mainly generated from the subgranular zone of the hippocampal dentate gyrus and the subependymal zones of the lateral ventricles. ${ }^{24}$ Traumatic brain injury leads to the migration of neuronal stem cells to the damaged sites to promote regeneration, thereby differentiating into astrocytes, neurons, and oligodendrocytes. Additionally, neuronal stem cells could release cytokines and neurotrophic factors such as glial cell-derived neurotrophic factor (GDNF) and brain-derived neurotrophic factor (BDNF). ${ }^{24}$ Thus neuronal stem cells may be an effective treatment for neurological recovery after TBI. ${ }^{52}$ Interestingly, neuronal stem cells show a high expression of oncogenic genes and high sensitivity to chemical mutagenic factors. ${ }^{24}$ This is important because stem cells are involved in the production of ROS and various pro-inflammatory factors. ${ }^{24}$ Neuronal stem cells can be highly sensitive to mutagenic agents and could, thus, be easily mutated as a result of the action of certain agents. These characteristics may promote the formation of rapidly proliferating tumor cells and increase the progression of glioma in the brain. ${ }^{24,53}$ Migration of stem cells has already been identified in cases of traumatic brain injury, ischemia, and demyelination. However, there is a much higher risk of increased neoplastic transformation only during traumatic brain injury. ${ }^{24}$ Therefore, it is reasonable to accept the causal relationship between traumatic brain injury that induces brain stem cell activity and subsequent development of glioma. ${ }^{24}$ Stem cells have been generally recognized as potentially oncogenic in glioma ${ }^{54}$ and several studies have demonstrated their important role in the formation of gliomas. ${ }^{55-57}$ The role of stem cells should be emphasized in the analysis of relevant mechanisms leading to glioma development induced by traumatic brain injury.

\section{Role of Astrocytes}

Multiple studies have suggested that astrocytes play a key role in the pathogenesis of TBI. ${ }^{58,59}$ Increased reactive astrocytes and astrocyte-derived factors are generally observed in both experimental animal models and TBI patients. ${ }^{60}$ Astrocytes have beneficial and detrimental effects on TBI, including acceleration and suppression of neuroinflammation, promotion and restriction of neurogenesis and synaptogenesis, and disruption and repair of the BBB through various bioactive factors. ${ }^{61}$ Additionally, astrocytic aquaporin-4 is also involved in the formation of cytotoxic edema. Thus, astrocytes are attractive targets for novel therapeutic drugs for TBI.

Based on case reports studying glioblastomas, neoplastic transformation of damaged astrocytes has been proposed as a possible mechanism occurring at the site of traumatic brain injuries. ${ }^{15-27}$ Besides, it is generally 
accepted that astrocytes are essential components of the blood-brain barrier, and damage to the blood-brain barrier often occurs after the action of pro-inflammatory prostaglandins and leukotrienes, which triggers the effect of the relaxing of tight junctions. ${ }^{54}$ The pro-inflammatory factors lead to a relaxation of the capillary epithelium and the glial cells are exposed to potentially mutagenic agents. ${ }^{62}$ Traumatic brain injury accompanied by damage to the blood-brain barrier always causes a recovery reaction, which explains the recurrence of glioma in some cases.

To conclude, the summary of various carcinogenic factors that play a role during traumatic brain injury is presented in Figure 1. Traumatic brain injury can lead to the influx of macrophages to the site of brain injury, where they are activated and produce IL-6. Traumatic brain injury also induces enhanced IL-6 secretion by astrocytes and microglial cells. Increased IL-6 levels caused by traumatic brain injury can thus activate STAT3, thereby increasing cell proliferation at the site of injury and resulting in the inhibition of apoptosis. STAT3 can suppress $\mathrm{T}$ lymphocytes and decrease the activity of MHC class II molecules on cells of the immune system. Furthermore, the increased levels of IL- 6 also impact the blood-brain barrier. Additionally, microglial cells secrete metalloproteinases in the tissues adjacent to the tumor, facilitating its migration and, consequently, facilitating its development. PGE2, which is synthesized by microglial cells during the development of the glioma, suppresses the T lymphocytes and decreases the expression of MHC II molecules. Besides, the generation of reactive oxygen species (ROS) might lead to certain mutations in stem cells that migrate to the injury site. At the site of injury, the risk of mutations and cell proliferation increases, and along with the inhibition of apoptosis, these factors may jointly contribute to carcinogenesis.

\section{Common Inflammatory and Oxidative Stress Signaling Pathways in Traumatic Brain Injury and Glioma}

Inflammation at the site of traumatic brain injury and glioma has been well documented in the literature. ${ }^{63,64}$ Besides, ROS, the major contributor of oxidative stress, are metabolic byproducts originating from different sources in hypoxic ${ }^{65}$ conditions and exhibit conditiondependent functions. ${ }^{66,67}$ The activation of inflammation and oxidative stress are reported in both traumatic brain injury and glioma, and both conditions appear to share a common network of signaling for downstream functions (Figure 2). Interestingly, the activation of inflammation can also contribute to oncogenesis via the generation of ROS and the activation of oxidative stress,${ }^{68}$ and conversely, oxidative stress also promotes inflammation. ${ }^{69}$ Specifically, in this situation, astrocytes, microglia, stem cells, and even neurons can be stimulated to increase ROS and RNS (NO, $\left.\mathrm{ONOO}^{-}\right),{ }^{70-72}$ which participate in regulating inflammation and oxidative stress in traumatic brain injury and glioma.

After traumatic brain injury, there is sequential migration of the resident microglia and myeloid inflammatory cells to the site of injury. ${ }^{73}$ These inflammatory cells contribute to oncogenesis via promoting ROS generation, which has mutagenic properties, or via the secretion of cytokines and growth factors, in addition to maintaining an inflammatory response. $^{68}$ During oxidative stress or inflammation in the brain, there is an increase in ROS could generation in the mitochondria. ${ }^{74-76}$ Several cancerspecific external stimuli, including TNF- $\alpha$, lead to a decrease in the mitochondrial membrane potential and interfere with the components of the electron transport chain (ETC), thereby promoting ROS generation. ${ }^{77,78}$ Besides, the NADPH oxidase (NOXs) protein family is one of the main producers of ROS in various cancers and traumatic brain injuries. ${ }^{79}$ Moreover, specific markers, such as TGF- $\beta$, MAPK, AKT, and ERK, among others, ${ }^{80,81}$ can lead to conformational changes in the NOX complex and increase ROS generation. ${ }^{82}$ Another indispensable pathway that has an impact on glioma and traumatic brain injury is hypoxia-inducing factor 1 (HIF1), which can be upregulated owing to the inhibition of degradation via the inactivation of PHD. ${ }^{83,84}$ HIF-1 increases the expression of glucose transporter 3 (GLUT3), erythropoietin (EPO), VEGF, and BNIP3. ${ }^{85-88}$ Several other signaling pathways are involved in the activation of inflammation and oxidative stress. Nuclear factor- $\kappa \mathrm{B}(\mathrm{NF}-\kappa \mathrm{B})$ can increase ROS generation via a positive feedback loop of TNF regulation. ${ }^{89}$ Additionally, ROS can be regulated by the Ras-Raf-MEK pathway through the transcriptional regulation of GATA$6 .{ }^{90,91}$ It has been reported that transcriptional enhancement of HSF1 by Ras upregulates SESN1 and SESN3 genes to promote ROS production. ${ }^{92}$ Besides, TGF $\beta$ also increases the production of ROS by activating the GSK3 $\beta$ and mTOR signaling pathways in the mitochondria and inhibiting antioxidant enzymes, including SOD and glutathione peroxidase (GPx) (Figure 2). ${ }^{93,94}$ 


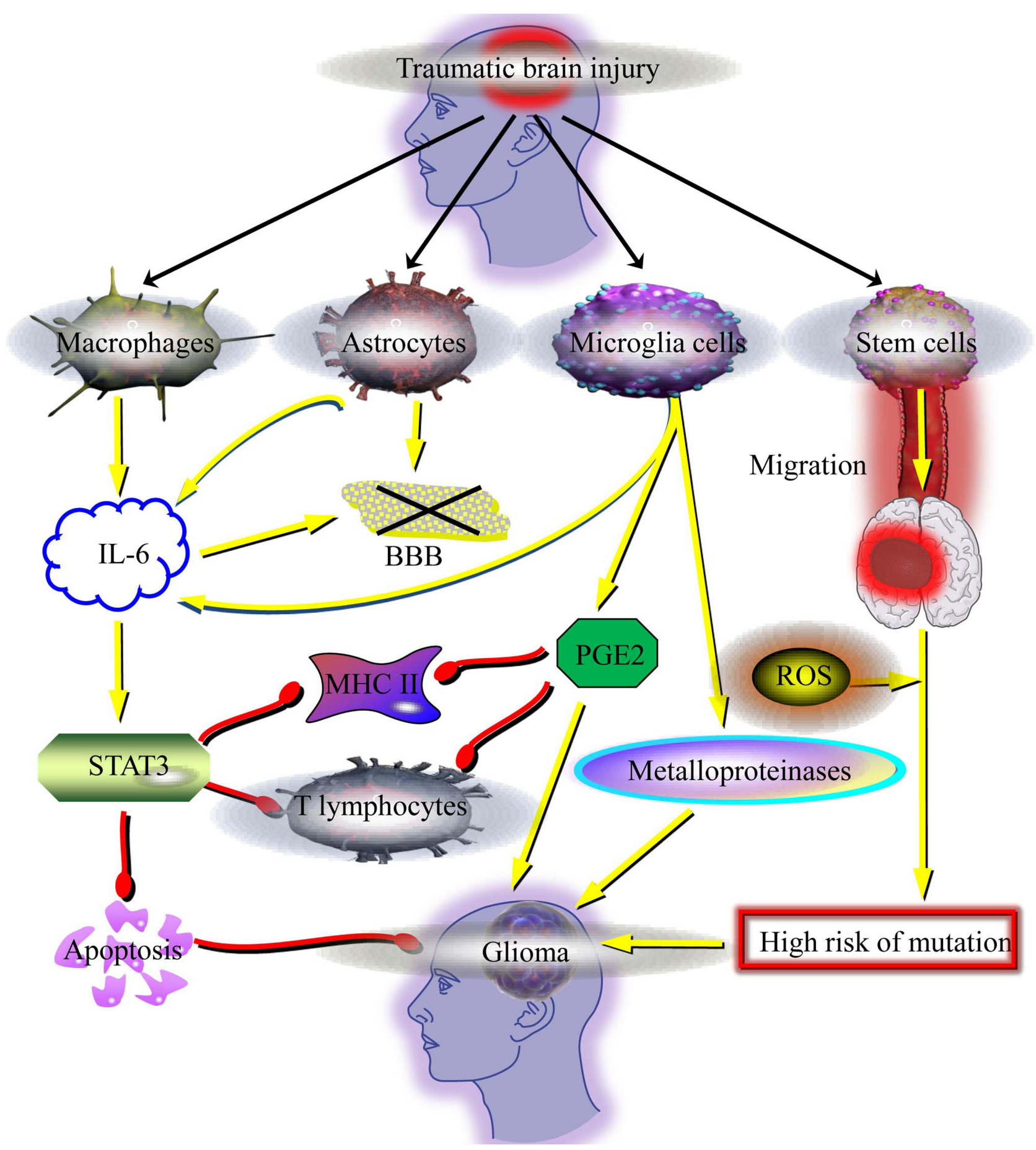

Figure I Schematic representation of various carcinogenic factors during traumatic brain injury. Traumatic brain injury could lead to the migration of macrophages to the site of injury, followed by increased IL-6 production. Traumatic brain injury also induces enhanced IL-6 secretion by astrocytes and microglial cells. The increased IL- 6 could thus activate STAT3, which increases cell proliferation at the site of injury, as well as inhibition of apoptosis. STAT3 suppresses T lymphocytes and inhibits major histocompatibility complex (MHC) class II molecules on cells of the immune system. The increased IL-6 also damages the blood-brain barrier (BBB). In addition, microglia secretes metalloproteinases in the tissues adjacent to the tumor, facilitating its migration and development. PGE2 is also synthesized by microglia and suppress T lymphocytes, and also decrease the expression of MHC II molecules on antigen-presenting cells. Besides, reactive oxygen species (ROS) might lead to certain mutations in stem cells that migrate to the site of injury. At the site of injury, the risk of these mutations, and cell proliferation increase, as well as the apoptosis inhibition, may jointly contribute to carcinogenesis. 


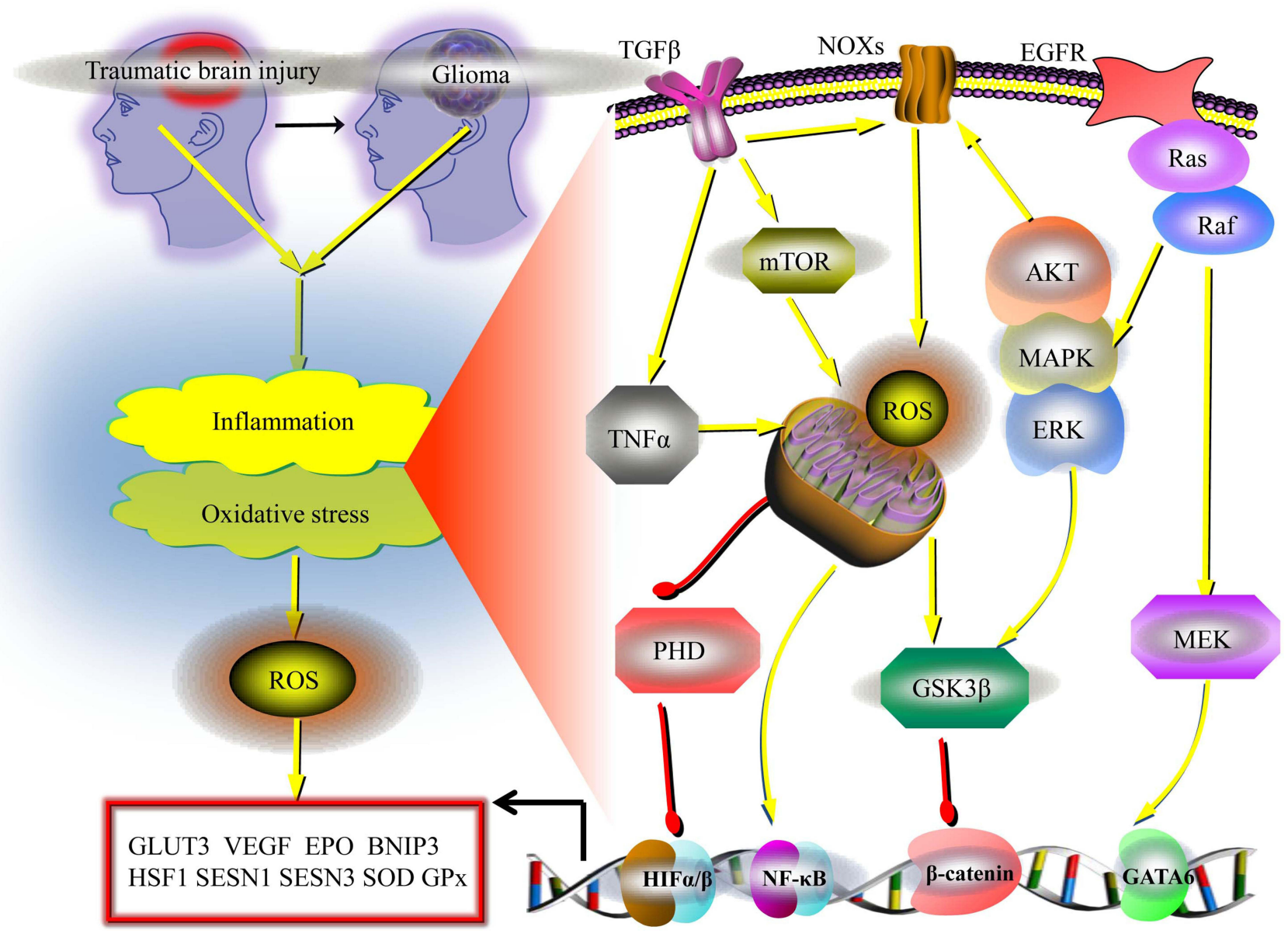

Figure 2 Common inflammatory and oxidative stress-related signaling pathways for traumatic brain injury and glioma. Activation of inflammation and oxidative stress are reported in both traumatic brain injury and glioma, and both conditions share a common network of signaling for downstream functions. Specifically, in the cases of oxidative stress or inflammation in the brain, more ROS could thus be generated. Several cancer-specific external stimuli like the TNF- $\alpha$, could lead to a decrease in the mitochondrial membrane potential that activates ROS generation. Besides, the NADPH oxidase (NOXs) family proteins are one of the main producers of ROS in various cancers, as well as in traumatic brain injuries. And specific signals like TGF- $\beta$, MAPK, AKT, ERK and various others, could lead to conformational changes in the NOX complex and increase ROS generation. Another important pathway that acts on glioma and traumatic brain injury in a similar manner is hypoxia-inducing factor I (HIF-I), which could be upregulated due to the inhibition of degradation via PHD inactivation. HIF-I could increase the expression of glucose transporter 3 (GLUT3), erythropoietin (EPO), VEGF, as well as BNIP3. Besides, nuclear factor- $\mathrm{B}$ (NF- $\kappa \mathrm{B}$ ) can increase the production of ROS, which can also be regulated by the Ras-Raf-MEK pathway via regulating GATA-6. Transcriptional enhancement of HSFI by Ras could activate the SESNI and SESN3 genes to promote the production of ROS. TGF $\beta$ also increases the production of ROS through activating GSK3 $\beta$ and mTOR signaling pathways in mitochondria, as well as inhibiting antioxidant enzymes, like the SOD and glutathione peroxidase (GPx).

\section{Clinical Approach and Future Research}

Following a traumatic brain injury, there is an increase in free radicals and the expression of several pro-inflammatory genes by various transcription factors such as NF- $\kappa \mathrm{B} .{ }^{95,96}$ This knowledge could be used in anticancer drug discovery. ROS levels increased by "oxidation therapy" can trigger cell death via necrosis or apoptosis. ${ }^{97}$ Flavonoids, such as quercetin, ${ }^{98,99}$ catechins, ${ }^{100}$ and proanthocyanins, ${ }^{101,102}$ protect glial cells from inflammation and oxidative stress. These compounds exert protective effects in the brains of patients with cancer and help prevent traumatic brain injury. An anticancer agent, gallic acid, is not only toxic to glioma cells but also exerts beneficial effects in the recovery from traumatic brain injuries. ${ }^{103-105}$ Cardamonin (a chalcone) is effective as an anti-inflammatory and anti-carcinogenic agent in glioma. ${ }^{106,107}$ Hyperbaric oxygen (HBO) therapy is a recently developed method ${ }^{108}$ that has been extensively used as an adjuvant in the treatment of various diseases predominantly related to hypoxic conditions. As traumatic brain injury and glioma are related to hypoxia, HBO therapy may be expected to be efficacious in the management of these diseases. ${ }^{109-111}$ However, there could be significant differences in outcomes among patients, depending on the size of the lesion, tumor type, and malignancy. ${ }^{112-114}$ Besides, several drugs, including glycyrrhizin, ${ }^{115}$ 


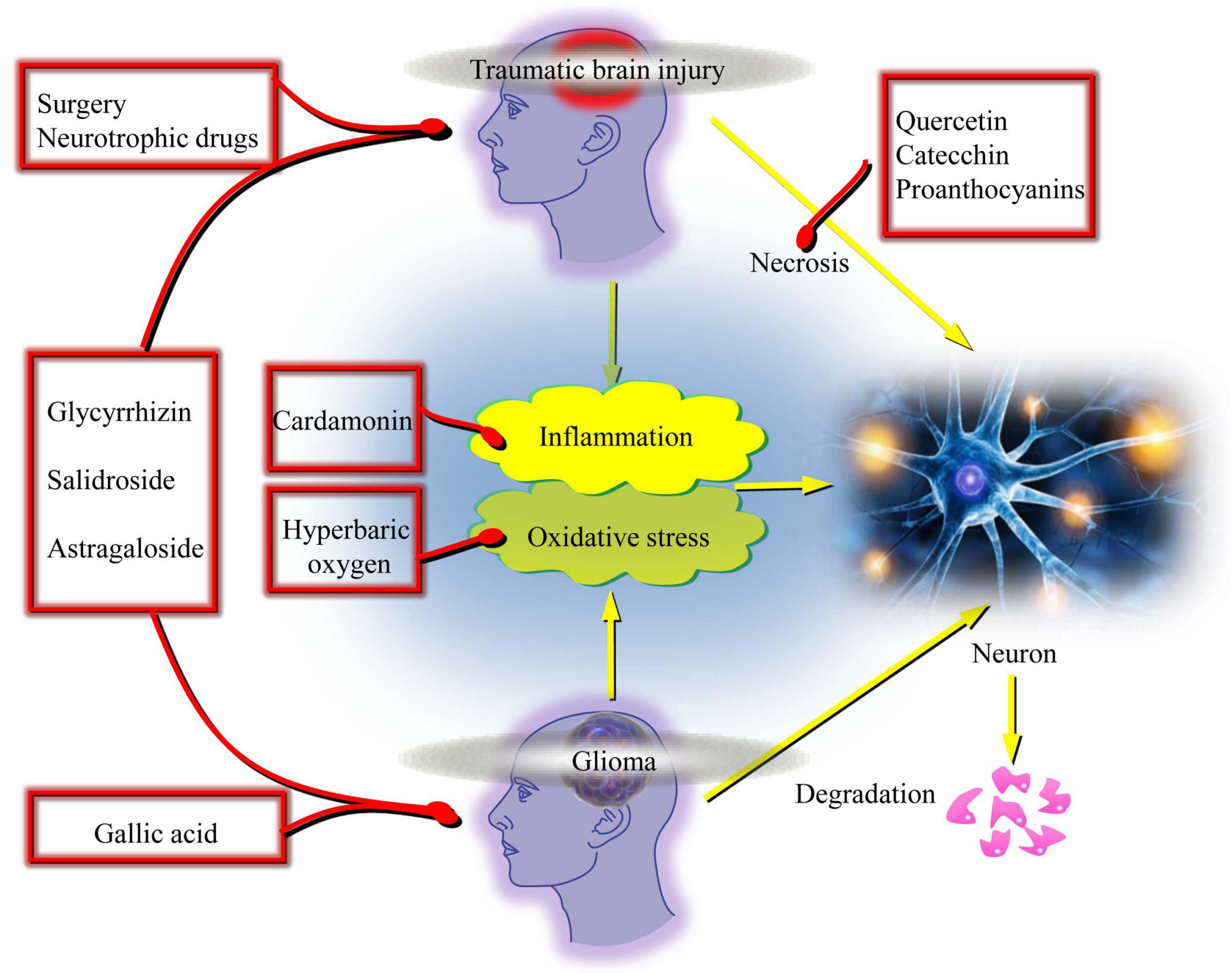

Figure 3 Selected common therapeutic approaches applied for both glioma and traumatic brain injury. An anticancer agent, gallic acid, could be of great toxic effects on glioma cells, and together exerts beneficial effects on recovery of traumatic brain injuries. Cardamonin (a chalcone) indicates effective anti-inflammatory and anticarcinogenic activity in glioma. Hyperbaric oxygen (HBO) therapy is a recently developed method that has been extensively used as an adjunctive treatment for various diseases predominantly related to hypoxic conditions, and could be effective for treatment of both glioma and traumatic brain injury. Besides, several other kinds of drugs, like the glycyrrhizin, salidroside and astragaloside, could be used in both glioma and traumatic brain injury treatment due to the counteracting effect of common signaling pathways. Several flavonoids such as quercetin, catechins, and proanthocyanins also protect the glial cells from inflammation and oxidative stress, and could be potentially effective for treatment of these two diseases.

salidroside, ${ }^{116-118}$ and astragaloside, ${ }^{119,120}$ may be used in both glioma and traumatic brain injury treatment due to the counteracting effect of common signaling pathways (Figure 3).

Currently, comprehensive research establishing the relationship between the mechanisms of traumatic brain injury and tumorigenesis is necessary. However, there could be some obstacles. First, the considerable time interval between brain injury and the onset of glioma poses a challenge to perform in vivo studies. Secondly, designing in vitro studies using primary cultures can also be difficult owing to a large number of different types of cells that constitute the brain tissue. The use of immortalized glial cell lines is also excluded owing to their physiological dissimilarity with normal brain cells. Therefore, more efforts should be directed toward establishing suitable in vivo and in vitro models to explore the causal relationship between traumatic brain injury and glioma.

\section{Conclusion}

The possible association between traumatic brain injury and glioma should be further examined by designing additional experimental and clinical research. Much more additional factors may be involved in the formation of the posttraumatic glioma. These factors might have been unintentionally omitted during the selection of study groups in various 
previous studies, leading to the result of the lack of connection between injury and glioma, which is why further explorations on the etiology of post-traumatic glioma are urgently needed. Besides, it may be more difficult to effectively treat patients who suffer from both glioma and traumatic brain injury compared to those with traumatic brain injury without glioma. The survival rate of patients with glioma is bound to increase with the development of anticancer drugs, including those suggested in this review. Treating traumatic brain injury in patients with glioma can be still challenging and requires specific treatment modalities. Thus, the development of effective strategies in the management of traumatic brain injury in patients with glioma is essential.

\section{Copyright/Ethics Statement}

The authors warrant that the article and all figures included in this work are the authors' original work and has not been published before.

\section{Disclosure}

The authors declare no competing financial interests and no conflicts of interest for this work.

\section{References}

1. Iaccarino C, Carretta A, Nicolosi F, Morselli C. Epidemiology of severe traumatic brain injury. J Neurosurg Sci. 2018;62:535-541. doi:10.23736/S0390-5616.18.04532-0

2. Dewan MC, Rattani A, Gupta S, et al. Estimating the global incidence of traumatic brain injury. $J$ Neurosurg. 2019;130:1080-1097. doi:10.3171/2017.10.JNS17352

3. Hay JR, Johnson VE, Young AM, Smith DH, Stewart W. Blood-Brain barrier disruption is an early event that may persist for many years after traumatic brain injury in humans. $J$ Neuropathol Exp Neurol. 2015;74:1147-1157.

4. Gardner RC, Yaffe K. Epidemiology of mild traumatic brain injury and neurodegenerative disease. Mol Cell Neurosci. 2015;66:75-80. doi:10.1016/j.men.2015.03.001

5. Munch TN, Gørtz S, Wohlfahrt J, Melbye M. The long-term risk of malignant astrocytic tumors after structural brain injury-a nationwide cohort study. Neuro Oncol. 2015;17(5):718-724. doi:10.1093/neuonc/ nou 312

6. Chen YH, Keller JJ, Kang JH, Lin HC. Association between traumatic brain injury and the subsequent risk of brain cancer. $J$ Neurotrauma 2012;29(7):1328-1333. doi:10.1089/neu.2011. 2235

7. Nygren C, Adami J, Ye W, Bellocco R. Primary brain tumors following traumatic brain injury-a population-based cohort study in Sweden. Cancer Causes Control. 2001;12(8):733-737. doi:10.1023/ A:1011227617256

8. Inskip PD, Mellemkjaer L, Gridley G, Olsen JH. Incidence of intracranial tumors following hospitalization for head injuries (Denmark). Cancer Causes Control. 1998;9(1):109-116. doi:10. 1023/A:1008861722901

9. Zampieri P, Meneghini F, Grigoletto F, et al. Risk factors for cerebral glioma in adults: a case-control study in an Italian population. J Neurooncol. 1994;19(1):61-67. doi:10.1007/BF01051049
10. Preston-Martin S, Pogoda JM, Schlehofer B, et al. An international case-control study of adult glioma and meningioma: the role of head trauma. Int $J$ Epidemiol. 1998;27(4):579-586. doi:10.1093/ije/27.4.579

11. Hu J, Johnson KC, Mao Y, et al. Risk factors for glioma in adults: a case-control study in northeast China. Cancer Detect Prev. 1998;22(2):100-108. doi:10.1046/j.1525-1500.1998.CDOA22.x

12. Hochberg F, Toniolo P, Cole P. Head trauma and seizures as risk factors of glioblastoma. Neurology. 1984;34(11):1511-1514. doi:10.1212/WNL.34.11.1511

13. Johansen C. Mind as a risk factor for cancer-some comments. Psychooncology. 2012;21:922-926. doi:10.1002/pon.3143

14. Mann CJ. Observational research methods. Research design II: cohort, cross sectional, and case-control studies. Emerg Med J. 2003;20:54-60. doi:10.1136/emj.20.1.54

15. Anselmi E, Vallisa D, Bertè R, Vanzo C, Cavanna L. Posttraumatic glioma: report of two cases. Tumori. 2006;92 (2):175-177. doi:10.1177/030089160609200215

16. Di Trapani G, Carnevale A, Scerrati M, Colosimo C, Vaccario ML, Mei D. Post-traumatic malignant glioma. Report of a case. Ital J Neurol Sci. 1996;17(4):283-286. doi:10.1007/ BF01997787

17. Magnavita N, Placentino RA, Mei D, Ferraro D, Di Trapani G. Occupational head injury and subsequent glioma. Neurol Sci. 2003;24(1):31-33. doi:10.1007/s100720300018

18. Moorthy RK, Rajshekhar V. Development of glioblastoma multiforme following traumatic cerebral contusion: case report and review of literature. Surg Neurol. 2004;61(2):180-184. doi:10.10 16/S0090-3019(03)00423-3

19. Mrowka R, Bogunska C, Kulesza J, Bazowski P, Wencel T. Grave cranio-cerebral trauma 30 years ago as cause of the brain glioma at the locus of the trauma particulars of the case. Zentralbl Neurochir. 1978;39(1):57-64.

20. Sabel M, Felsberg J, Messing-Junger M, Neuen-Jacob E, Piek J. Glioblastoma multiforme at the site of metal splinter injury: a coincidence? Case report. J Neurosurg. 1999;91(6):10 41-1044. doi:10.3171/jns.1999.91.6.1041

21. Witzmann A, Jellinger K, Weiss R. Glioblastoma multiformedeveloping after a gunshot injury of the brain (author's transl). Neurochirurgia. 1981;24(6):202-206.

22. Zhou B, Liu W. Post-traumatic glioma: report of one case and review of the literature. Int J Med Sci. 2010;7(5):248-250. doi:10.7150/ijms.7.248

23. Han Z, Du Y, Qi H, Yin W. Post-traumatic malignant glioma in a pregnant woman: case report and review of the literature. Neurol Med Chir (Tokyo). 2013;53(9):630-634. doi:10.2176/ nmc.cr2013-0029

24. Tyagi $\mathrm{V}$, Theobald $\mathrm{J}$, Barger $\mathrm{J}$, et al. Traumatic brain injury and subsequent glioblastoma development: review of the literature and case reports. Surg Neurol Int. 2016;26:77-78.

25. Salvati M, Caroli E, Rocchi G, Frati A, Brogna C, Orlando ER. Post-traumatic glioma. Report of four cases and review of the literature. Tumori J. 2004;90:416-419. doi:10.1177/ 030089160409000410

26. Henry PT, Rajshekhar V. Post-traumatic malignant glioma: case report and review of the literature. $\mathrm{Br} J$ Neurosurg. 2000;14:64-67. doi:10.1080/02688690042979

27. Simińska D, Kojder K, Jeżewski D, et al. The Pathophysiology of Post-Traumatic Glioma. Int J Mol Sci. 2018;19(8):2445. doi:10.3390/ijms 19082445

28. Liao Y, Liu P, Guo F, Zhang ZY, Zhang Z. Oxidative burst of circulating neutrophils following traumatic brain injury in human. PLoS One. 2013;8:e68963. doi:10.1371/journal.pone.0068963

29. Woodcock T, Morganti-Kossmann MC. The role of markers of inflammation in traumatic brain injury. Front Neurol. 2013;4:1-5. doi:10.3389/fneur.2013.00018 
30. Ewing J. The Bulkley Lecture. The modern attitude toward traumatic cancer. Bull New York Academy Med. 1935;11:281-333.

31. Ohana N, Benharroch D, Sheinis D, Cohen A. Traumatic glioblastoma: commentary and suggested mechanism. J Int Med Res. 2018;46(6):2170-2176. doi:10.1177/0300060518771265

32. Moorthy RK, Rajshekhar V. Development of glioblastoma multiforme following traumatic cerebral contusion: case report and review of literature. Surg Neurol. 2001;61:180-184.

33. Witcher KG, Bray CE, Dziabis JE, et al. Traumatic brain injury-induced neuronal damage in the somatosensory cortex causes formation of rod-shaped microglia that promote astrogliosis and persistent neuroinflammation. Glia. 2018;66(12):27 19-2736. doi:10.1002/glia.23523

34. Xiong XY, Liu L, Yang QW. Functions and mechanisms of microglia/macrophages in neuroinflammation and neurogenesis after stroke. Prog Neurobiol. 2016;142:23-44.

35. Simon DW, McGeachy MJ, Bayır H, Clark RS, Loane DJ, Kochanek PM. The far-reaching scope of neuroinflammation after traumatic brain injury. Nat Rev Neurol. 2017;13(3):171-191.

36. Loane DJ, Kumar A. Microglia in the TBI brain: the good, the bad, and the dysregulated. Exp Neurol. 2016;275(3):316-327. doi:10.1016/j.expneurol.2015.08.018

37. Cherry JD, Olschowka JA, O'Banion MK. Neuroinflammation and M2 microglia: the good, the bad, and the inflamed. $J$ Neuroinflammation. 2014;11:98. doi:10.1186/1742-2094-11-98

38. Kobayashi K, Imagama S, Ohgomori T, et al. Minocycline selectively inhibits M1 polarization of microglia. Cell Death Dis. 2013;4:e525. doi:10.1038/cddis.2013.54

39. Qin H, Yeh WI, De Sarno P, et al. Signal transducer and activator of transcription-3/suppressor of cytokine signaling-3 (STAT3/ SOCS3) axis in myeloid cells regulates neuroinflammation. Proc Natl Acad Sci U S A. 2012;109:5004-5009. doi:10.1073/ pnas. 1117218109

40. Tanaka T, Murakami K, Bando Y, Yoshida S. Interferon regulatory factor 7 participates in the M1-like microglial polarization switch. Glia. 2015;63:595-610. doi:10.1002/glia.22770

41. Xu H, Wang Z, Li J, et al. The polarization states of microglia in TBI: a new paradigm for pharmacological intervention. Neural Plast. 2017;2017:5405104. doi:10.1155/2017/5405104

42. Xu B, Yu DM, Liu FS. Effect of siRNA induced inhibition of IL 6 expression in rat cerebral gliocytes on cerebral edema following traumatic brain injury. Mol Med Rep. 2014;10:1863-1868. doi: $10.3892 / \mathrm{mmr} .2014 .2462$

43. Li W, Graeber MB. The molecular profile of microglia under the influence of glioma. Neuro Oncol. 2012;14:958-978.

44. Markovic DS, Vinnakota K, Chirasani S, et al. Gliomas induce and exploit microglial MT1-MMP expression for tumor expansion. Proc Natl Acad Sci USA. 2009;106:12530-12535. doi: $10.1073 /$ pnas. 0804273106

45. Zhai H, Heppner FL, Tsirka SE. Microglia/macrophages promote glioma progression. Glia. 2011;59:472-485. doi:10.1002/glia.21117

46. Sawamura Y, Diserens AC, de Tribolet N. In vitro prostaglandin E2 production by glioblastoma cells and ist effect on IL2 activation of oncolytic lymphocytes. J Neuroncol. 1990;9:125-130. doi:10.1007/BF02427832

47. Ma MW, Wang J, Dhandapani KM, Wang R, Brann DW. NADPH oxidases in traumatic brain injury-Promising therapeutic targets? Redox Biol. 2018;16:285-293. doi:10.1016/j.redox.2018.03.005

48. Li Z, Xiao J, Xu X, et al. M-CSF, IL-6, and TGF-beta promote generation of a new subset of tissue repair macrophage for traumatic brain injury recovery. Sci Adv. 2021;7(11):eabb6260. doi:10.1126/sciadv.abb6260

49. Li Z, Xiao J, Xu X, et al. M-CSF, IL-6, and TGF-beta promote generation of a new subset of tissue repair macrophage for traumatic brain injury recovery. Sci Adv. 2021;7(11):eabb6260.
50. Chen F, Xu Y, Luo Y, et al. Down-regulation of Stat3 decreases invasion activity and induces apoptosis of human glioma cells. J Mol Neurosci. 2010;40:353359. doi:10.1007/s12031-009-9323-3

51. Iwamaru A, Szymanski S, Iwado E, et al. A novel inhibitor of the STAT3 pathway induces apoptosis in malignant glioma cells both in vitro and in vivo. Oncogene. 2007;26:2435-2444. doi:10.1038/ sj.onc. 1210031

52. Haus DL, López-Velázquez L, Gold EM, et al. Transplantation of human neural stem cells restores cognition in an immunodeficient rodent model of traumatic brain injury. Exp Neurol. 2016; 281:1-16. doi:10.1016/j.expneurol.2016.04.008

53. Korbecki J, Gutowska I, Kojder I, et al. New extracellular factors in glioblastoma multiforme development: neurotensin, growth differentiation factor-15, sphingosine-1-phosphate and cytomegalovirus infection. Oncotarget. 2018;9:7219-7270. doi:10.18632/ oncotarget. 24102

54. Bohman LE, Swanson KR, Moore JL, et al. Magnetic Resonance imaging characteristics of glioblastoma multiforme: implications for understanding gliomna ontogeny. Neurosurgery. 2010;67:13 19-1328. doi:10.1227/NEU.0b013e3181f556ab

55. Gil-Perotin S, Marin-Husstege M, Li J, et al. Loss of p53 induces changes in the behavior of subventricular zone cells: implication for the genesis of glial tumors. $J$ Neurosci. 2006;26:1107-1116. doi:10.1523/JNEUROSCI.3970-05.2006

56. Jackson EL, Garcia-Verdugo JM, Gil-Perotin S, et al. PDGFR alpha-positive B cells are neural stem cells in the adults SVZ that form glioma like growths in response to increased PDGF signaling. Neuron. 2006;51:187-199. doi:10.1016/j. neuron.2006.06.012

57. Assanah M, Lochhead R, Ogden A, Bruce J, Goldman J, Canoll P. Glial progenitors in adult white matter are driven to form malignant gliomas by platelet-derived growth factor-expressing retroviruses. $J$ Naurosci. 2006;26:6781-6790. doi:10.1523/ JNEUROSCI.0514-06.2006

58. Burda JE, Bernstein AM, Sofroniew MV. Astrocyte roles in traumatic brain injury. Exp Neurol. 2016;275(Pt 3):305-315. doi:10.1016/j.expneurol.2015.03.020

59. Xu H, Fang T, Omran RP, Whiteway M, Jiang L. RNA sequencing reveals an additional Crz1-binding motif in promoters of its target genes in the human fungal pathogen Candida albicans. Cell Commun Signal. 2020;18:1. doi:10.1186/s12964-019-0473-9

60. Castejón OJ. Morphological astrocytic changes in complicated human brain trauma. A light and electron microscopic study. Brain Inj. 1998;12(5):409-427. doi:10.1080/026990598122539

61. Michinaga S, Pathophysiological Responses KY. Roles of astrocytes in traumatic brain injury. Int $J$ Mol Sci. 2021;22(12):6418. doi:10.3390/ijms 22126418

62. Patel JP, Frey BN. Disruption in the blood-brain barrier: the missing link between brain and body inflammation in bipolar disorder? Neural Plast. 2015;2:708306.

63. Murray KN, Parry-Jones AR, Allan SM. Interleukin-1 and acute brain injury. Front Cell Neurosci. 2015;9:18. doi:10.3389/ fncel.2015.00018

64. Ross JL, Chen Z, Herting CJ, et al. Platelet-derived growth factor beta is a potent inflammatory driver in paediatric high-grade glioma. Brain. 2020;54:awaa382.

65. Ray PD, Huang BW, Tsuji Y. Reactive oxygen species (ROS) homeostasis and redox regulation in cellular signaling. Cell Signal. 2012;24:981-990. doi:10.1016/j.cellsig.2012.01.008

66. Rajaraman P, Melin BS, Wang Z, et al. Genome-wide association study of glioma and meta-analysis. Hum Genet. 2012;131:1877-1888. doi:10.1007/s00439-012-1212-0

67. Sanai N, Alvarez-Buylla A, Berger MS. Neural stem cells and the origin of gliomas. $N$ Engl J Med. 2005;353:811-822. doi:10.1056/ NEJMra043666 
68. Liao Y, Liu P, Guo F, Zhang ZY, Zhang Z. Oxidative burst of circulating neutrophils following traumatic brain injury in human. PLoS One. 2013;8:e68963.

69. Kawabori M, Yenari MA. Inflammatory responses in brain ischemia. Curr Med Chem. 2015;22:1258-1277. doi:10.2174/ 0929867322666150209154036

70. Schwartzbaum J, Ahlbom A, Malmer B, et al. Polymorphisms associated with asthma are inversely related to glioblastoma multiforme. Cancer Res. 2005;65:6459-6465. doi:10.1158/00085472.CAN-04-3728

71. Shete S, Hosking FJ, Robertson LB, et al. Genome-wide association study identifies five susceptibility loci for glioma. Nat Genet. 2009;41:899-904. doi:10.1038/ng.407

72. Simon M, Hosking FJ, Marie Y, et al. Genetic risk profiles identify different molecular etiologies for glioma. Clin Cancer Res. 2010;16:5252-5259. doi:10.1158/1078-0432. CCR-10-1502

73. Johnson VE, Stewart JE, Begbie FD, Trojanowski JQ, Smith DH, Stewart W. Inflammation and white matter degeneration persist for years after a single traumatic brain injury. Brain. 2013;136(Pt 1):28-42. doi:10.1093/brain/aws322

74. Handy DE, Loscalzo J. Redox regulation of mitochondrial function. Antioxid Redox Signal. 2012;16:1323-1367. doi:10.10 89/ars.2011.4123

75. Yang JL, Mukda S, Chen SD. Diverse roles of mitochondria in ischemic stroke. Redox Biol. 2018;16:263-275. doi:10.1016/j. redox.2018.03.002

76. Zorov DB, Juhaszova M, Sollott SJ. Mitochondrial reactive oxygen species (ROS) and ROS-induced ROS release. Physiol Rev. 2014;94:909-950. doi:10.1152/physrev.00026.2013

77. Doll DN, Rellick SL, Barr TL, Ren X, Simpkins JW. Rapid mitochondrial dysfunction mediates TNF-alpha-induced neurotoxicity. $J$ Neurochem. 2015;132:443-451. doi:10.1111/ jnc. 13008

78. Sarafian TA, Montes C, Imura T, et al. Disruption of astrocyte STAT3 signaling decreases mitochondrial function and increases oxidative stress in vitro. PLoS One. 2010;5(3):e9532. doi:10.13 71/journal.pone.0009532

79. De Silva TM, Brait VH, Drummond GR, Sobey CG, Miller AA. Nox2 oxidase activity accounts for the oxidative stress and vasomotor dysfunction in mouse cerebral arteries following ischemic stroke. PLoS One. 2011;6:e28393. doi:10.1371/journal.pone.00 28393

80. Lou Z, Wang AP, Duan XM, et al. Upregulation of NOX2 and NOX4 mediated by TGF- $\beta$ signaling pathway exacerbates cerebral ischemia/reperfusion oxidative stress injury. Cell Physiol Biochem . 2018;46(5):2103-2113. doi:10.1159/000489450

81. Nakanishi A, Wada Y, Kitagishi Y, Matsuda S. Link between PI3K/AKT/PTEN pathway and NOX proteinin diseases. Aging Dis. 2014;5:203-211. doi:10.14336/AD.2014.0500203

82. Rastogi R, Geng X, Li F, Ding Y. NOX activation by subunit interaction and underlying mechanisms in disease. Front Cell Neurosci. 2017;10:301. doi:10.3389/fncel.2016.00301

83. Sharp FR, Bergeron M, Bernaudin M. Hypoxia-inducible factor in brain. Adv Exp Med Biol. 2001;502:273-291.

84. Singh N, Sharma G, Mishra V. Hypoxia inducible factor-1: its potential role in cerebral ischemia. Cell Mol Neurobiol. 2012;32:491-507. doi:10.1007/s10571-012-9803-9

85. Liu Y, Li YM, Tian RF, et al. The expression and significance of HIF-1alpha and GLUT-3 in glioma. Brain Res. 2009;13 04:149-154. doi:10.1016/j.brainres.2009.09.083

86. Kaur B, Khwaja FW, Severson EA, Matheny SL, Brat DJ, Van Meir EG. Hypoxia and the hypoxia-inducible-factor pathway in glioma growth and angiogenesis. Neuro Oncol. 2005;7:134-153. doi:10.1215/S1152851704001115
87. Souvenir R, Flores JJ, Ostrowski RP, Manaenko A, Duris K, Tang J. Erythropoietin inhibits HIF-1 $\alpha$ expression via upregulation of PHD-2 transcription and translation in an in-vitro model of hypoxia ischemia. Transl Stroke Res. 2014;5:118-127. doi:10. 1007/s12975-013-0312-z

88. Sowter HM, Ratcliffe PJ, Watson P, Greenberg AH, Harris AL. HIF-1 - dependent regulation of hypoxic induction of the cell death factors BNIP3 and NIX in huuman tumors. Cancer Res. 2001;61:6669-6673.

89. Blaser H, Dostert C, Mak TW, Brenner D. TNF and ROS crosstalk in inflammation. Trends Cell Biol. 2016;26:249-261. doi:10. 1016/j.tcb.2015.12.002

90. Adachi Y, Shibai Y, Mitsushita J, Shang WH, Hirose K, Kamata T. Oncogenic Ras upregulates NADPH oxidase 1 gene expression through MEK-ERK-dependent phosphorylation of GATA-6. Oncogene. 2008;27(36):4921-4932. doi:10.1038/onc.2008.133

91. Valente AJ, Zhou Q, Lu Z, et al. Regulation of NOX1 expression by GATA, HNF-1alpha, and Cdx transcription factors. Free Radic Biol Med. 2008;44:430-443. doi:10.1016/j.freeradbiomed.2007.10.035

92. Zamkova M, Khromova N, Kopnin BP, Kopnin P. Ras-induced ROS upregulation affecting cell proliferation is connected with cell type-specific alterations of HSF1/SESN3/p21 Cip1/WAF1 pathways. Cell Cycle. 2013;12(5):826-836. doi:10.4161/ cc. 23723

93. Byun HO, Jung HJ, Seo YH, et al. GSK3 inactivation is involved in mitochondrial complex IV defect in transforming growth factor (TGF) $\beta 1$-induced senescence. Exp Cell Res. 2012;318:18 08-1819. doi:10.1016/j.yexcr.2012.04.012

94. Jain M, Rivera S, Monclus EA, et al. Mitochondrial reactive oxygen species regulate transforming growth factor- $\beta$ signaling. J Biol Chem. 2013;288:770-777. doi:10.1074/jbc.M112.431973

95. Harari OA, Liao JK. NF- $\kappa \mathrm{B}$ and innate immunity in ischemic stroke. Ann N Y Acad Sci. 2010;1207:32-40. doi:10.1111/j.17496632.2010.05735.x

96. Xie H, Ray PE, Bl S. NF- $\mathrm{B}$ activation plays a role in superoxidemediated cerebral endothelial dysfunction after hypoxia/reoxygenation. Stroke. 2005;36(5):1047-1052. doi:10.1161/01.STR.00 00157664.34308.cc

97. Tew KD, Townsend DM. Redox platforms in cancer drug discovery and development. Curr Opin Chem Biol. 2011;15:156-161. doi:10.1016/j.cbpa.2010.10.016

98. Siegelin MD, Reuss DE, Habel A, Rami A, von Deimling A. Quercetin promotes degradation of survivin and thereby enhances deathreceptor-mediated apoptosis in glioma cells. Neuro Oncol. 2009;11:122-131. doi:10.1215/15228517-2008-085

99. Kim H, Moon JY, Ahn KS, Cho SK. Quercetin induces mitochondrial mediated apoptosis and protective autophagy in human glioblastoma U373MG cells. Oxid Med Cell Longev. 2013;23:596496

100. Vauzour D, Vafeiadou K, Rodriguez-Mateos A, Rendeiro C, Spencer JP. The neuroprotective potential of flavonoids: a multiplicity of effects. Genes Nutr. 2008;3:115-126. doi:10. 1007/s12263-008-0091-4

101. Erdem Y, Tekiner A, Erkoc YS, et al. Antiedema effects of proanthocyanidin on experimental traumatic brain edema. Turk Neurosurg. 2015;25(1):85-89.

102. ZhuGe DL, Wang LF, Chen R, et al. Cross-linked nanoparticles of silk fibroin with proanthocyanidins as a promising vehicle of indocyanine green for photo-thermal therapy of glioma. Artif Cells Nanomed Biotechnol. 2019;47(1):4293-4304. doi:10.1080/ 21691401.2019.1699819

103. Lee SH, Kim JK, Kim DW, et al. Antitumor activity of methyl gallate by inhibition of focal adhesion formation and Akt phosphorylation in glioma cells. Biochim Biophys Acta. 2013;1830:4017-4029. doi:10.1016/j.bbagen.2013.03.030 
104. Sun J, Li YZ, Ding YH, et al. Neuroprotective effects of gallic acid against hypoxia/reoxygenation-induced mitochondrial dysfunctions in vitro and cerebral ischemia/reperfusion injury in vivo. Brain Res. 2014;1589:126-139. doi:10.1016/j.brainres.20 14.09.039

105. Farbood Y, Sarkaki A, Hashemi S, Mansouri MT, Dianat M. The effects of gallic acid on pain and memory following transient global ischemia/reperfusion in Wistar rats. Avicenna. J Phytomed. 2013;3:329-340.

106. Jiang FS, Tian SS, Lu JJ, et al. Cardamonin regulates miR-21 expression and suppresses angiogenesis induced by vascular endothelial growth factor. Biomed Res Int. 2015;2015:501581. doi:10.1155/2015/501581

107. Kim YJ, Ko H, Park JS, et al. Dimethyl cardamonin inhibits lipopolysaccharide-induced inflammatory factors through blocking NF-kappaB p65 activation. Int Immunopharmacol. 2010;10:1127-1134. doi:10.1016/j.intimp.2010.06.017

108. Choudhury R. Hypoxia and hyperbaric oxygen therapy: a review. Int J Gen Med. 2018;Volume 11(11):431-442. doi:10.2147/IJGM. S172460

109. Chen JR, Xu HZ, Ding JB, Qin ZY. Radiotherapy after hyperbaric oxygenation in malignant gliomas. Curr Med Res Opin. 2015;31:1977-1984. doi:10.1185/03007995.2015.108 2988

110. Duan S, Shao G, Yu L, Ren C. Angiogenesis contributes to the neuroprotection induced by hyperbaric oxygen preconditioning against focal cerebral ischemia in rats. Int $J$ Neurosci. 2015;125:625-634. doi:10.3109/00207454.2014.956101

111. Michalski D, Härtig W, Schneider D, Hobohm C. Use of normobaric and hyperbaric oxygen in acute focal cerebral ischemia-a preclinical and clinical review. Acta Neurol Scand. 2011;123:85-97. doi:10.1111/j.1600-0404.20 10.01363.x
112. Wang YG, Zhan YP, Pan SY, et al. Hyperbaric oxygen promotes malignant glioma cell growth and inhibits cell apoptosis. Oncol Lett. 2015;10:189-195. doi:10.3892/ol.2015.3244

113. Stępień K, Ostrowski RP, Matyja E. Hyperbaric oxygen as an adjunctive therapy in treatment of malignancies, including brain tumours. Med Oncol. 2016;33:101. doi:10.1007/s12032-016-0814-0

114. Huang L, Boling W, Zhang JH. Hyperbaric oxygen therapy as adjunctive strategy in treatment of glioblastoma multiforme. Med Gas Res. 2018;8:24-28. doi:10.4103/20459912.229600

115. Gong G, Xiang L, Yuan L, et al. Protective effect of glycyrrhizin, a direct HMGB1 inhibitor, on focal cerebral ischemia/reperfusion-induced inflammation, oxidative stress, and apoptosis in rats. PLoS One. 2014;9:e89450. doi:10.1371/journal.pone.0089450

116. Liu X, Wen S, Yan F, et al. Salidroside provides neuroprotection by modulating microglial polarization after cerebral ischemia. J Neuroinflammation. 2018;15:39. doi:10.1186/s12974-018-1081-0

117. Zhang Y, Yao Y, Wang H, Guo Y, Zhang H, Chen L. Effects of salidroside on glioma formation and growth inhibition together with improvement of tumor microenvironment. Chin J Cancer Res. 2013;25:20-526.

118. Ni J, Li Y, Li W, Guo R. Salidroside protects against foam cell formation and apoptosis, possibly via the MAPK and AKT signaling pathways. Lipids Health Dis. 2017;16:198. doi:10.1186/ s12944-017-0582-7

119. Li B, Wang F, Liu N, Shen W, Huang T. Astragaloside IV inhibits progression of glioma via blocking MAPK/ERK signaling pathway. Biochem Biophys Res Commun. 2017;491:98-103. doi:10.1016/j.bbrc.2017.07.052

120. Li M, Qu YZ, Zhao ZW, et al. Astragaloside IV protects against focal cerebral ischemia/reperfusion injury correlating to suppression of neutrophils adhesion-related molecules. Neurochem Int. 2012;60:458-465. doi:10.1016/j.neuint.2012.01.026
Journal of Inflammation Research

\section{Publish your work in this journal}

The Journal of Inflammation Research is an international, peerreviewed open-access journal that welcomes laboratory and clinical findings on the molecular basis, cell biology and pharmacology of inflammation including original research, reviews, symposium reports, hypothesis formation and commentaries on: acute/chronic inflammation; mediators of inflammation; cellular processes; molecular mechanisms; pharmacology and novel anti-inflammatory drugs; clinical conditions involving inflammation. The manuscript management system is completely online and includes a very quick and fair peerreview system. Visit http://www.dovepress.com/testimonials.php to read real quotes from published authors. 